\title{
ESTABLISH A CRITERIA SET FOR ASSESSING THE FLOOD RISK AT OVERFLOW BRIDGE IN CENTRAL VIETNAM
}

\section{Hoang Ngoc Tuan*}

Central Viet Nam Institute for Water Resources. No. 132, Dong Da Street, Hai Chau District, Da Nang 50000, Vietnam.

\section{Nguyen Van Luc}

Central Viet Nam Institute for Water Resources. No. 132, Dong Da Street, Hai Chau District, Da Nang 50000, Vietnam.

\section{Hoang Nam Binh}

University of Transport and Communications. No 3, Caugiay Str., Dongda Dist., Hanoi 10000, Vietnam.

\section{Hoang Duc Vinh}

Key Laboratory of River and Coastal Engineering. No 1/165 Chuaboc Str., Dongda Dist., Hanoi 10000, Vietnam.

*Corresponding Author Email: tuan.vientl@gmail.com

\begin{abstract}
An overflow bridge is a drainage work in combination with a road, which is built across rivers and streams. In the rainy season, the flood flow over the work is both deep and fast, causing danger to the lives of people, vehicles, and even the overflow bridge itself. So far, in Vietnam there is no official statistics on the number of overflow bridges as well as tools / criteria for assessing their potential risks. This study collects 10 criteria from the three groups of hazard, vulnerability, and exposure to assess the danger level for overflow bridges which was applied in the central region of Vietnam. The weight of each factor is determined by AHP hierarchical analysis. The aggregated criteria value is classified into 3 levels as $C=1.0$ - 1.66 (Low danger); $C$ $=1.66-2.0$ (Medium danger) and $C=2.0-3.0$ (High danger). This set of criteria is the basis for the management agency to apply in alerting people to reduce flood risks as well as for repairing and upgrading overflow bridges.
\end{abstract}

Keywords: overflow bridge, flood risk, risk criteria, Central Vietnam, AHP 
Cite this Article: Hoang Ngoc Tuan, Nguyen Van Luc, Hoang Nam Binh and Hoang Duc Vinh, Establish a Criteria Set for Assessing the Flood Risk at Overflow Bridge in Central Vietnam, International Journal of Civil Engineering and Technology, 11(5), 2020, pp. 146-156.

https://iaeme.com/Home/issue/IJCIET?Volume=11\&Issue $=5$

\section{INTRODUCTION}

Vietnam is located in a tropical monsoon climate region, dense river network and a developing country. There are many spillways (overflow bridges) on the roads passing through rivers and streams. Every year, during the rainy season, many unfortunate accidents occur related to traffic through overflow bridge. According to data of the Disaster Prevention Department, in the past 10 years, flood flows on the overflow bridges have swept over 30 cars, hundreds of motorcycles, more than 100 people died and 357 works damaged.

Survey results at spillways in central Vietnam showed that most of overflow bridges are located in small basins, narrow terrain and slopes. Some works are located on the flood discharge route of the reservoirs. Most works in central Vietnam are not equipped with warning systems or flood warning columns. A few works have a flood warning column but the information is often difficult to observe (Figure 1). Therefore, when heavy rains or flooding from the reservoirs, the water flow will focus very quickly on the project. Due to the small aperture of flood drainage, flood usually overflows very quickly. Besides, the timing of flood occurrence and the level of flooding in the overflow area are difficult to accurately predict, so the authorities and local people have many difficulties in proactively preventing and minimizing damage.
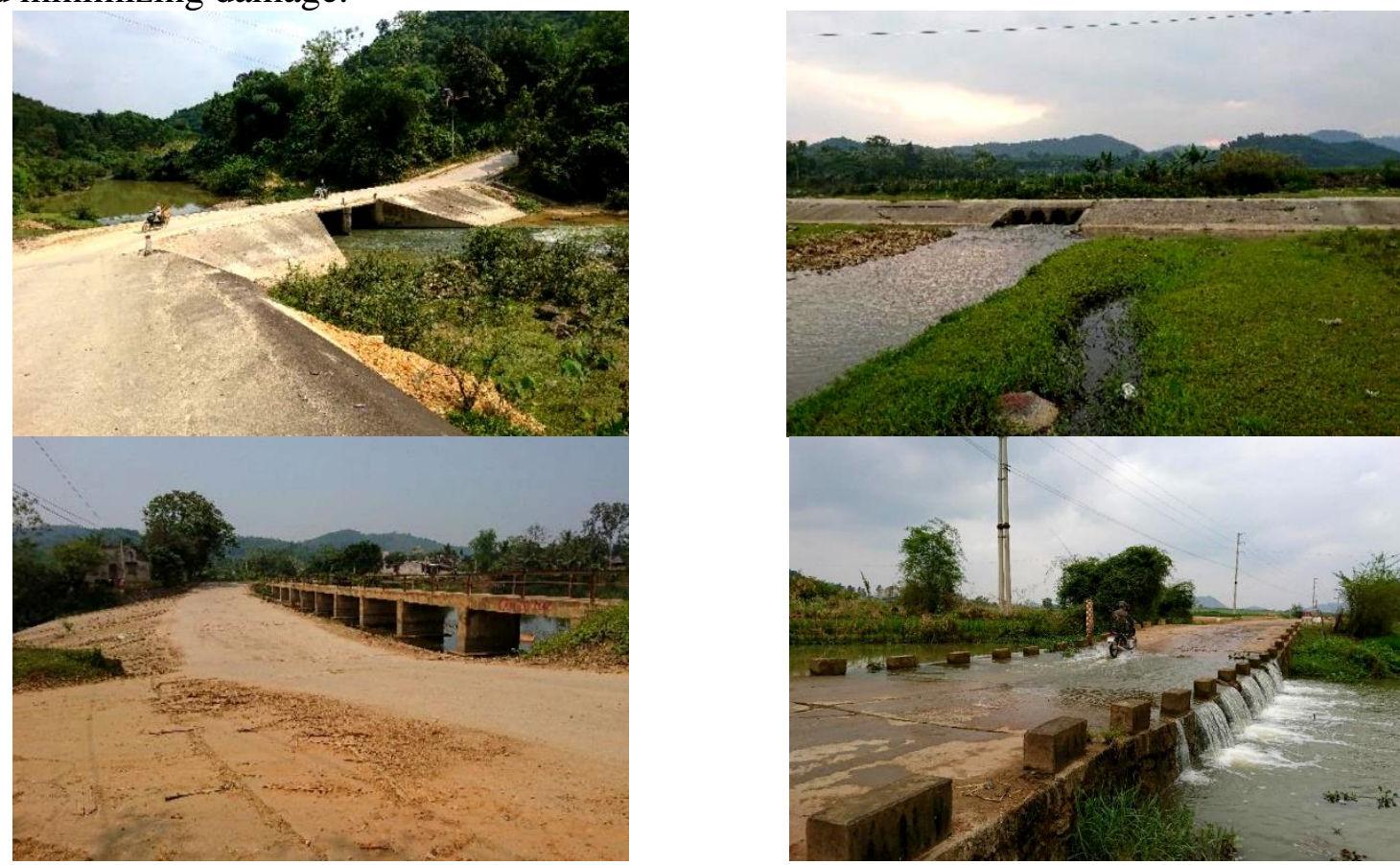

Figure 1 Typical types of overflow bridges in Central Vietnam

So far in Vietnam, damages to overflow bridges are often assessed based on actual data without considering the nature of the phenomenon. Quantification of the main causes of such damage has not been taken into account. In addition, Vietnam has not yet assessed their danger level to give appropriate warnings or remedies to minimize damage in each rainy season. Therefore, it is very necessary to have a solution to minimize the damage to the lowest level. The study proposed a set of criteria to assess the danger level of overflow 
bridges so that authorities could identify which works are in the alert zone and have a timely response plans.

\section{METHODOLOGY}

According to (Alexander, 1997), risk is a concept that presents potentially negative effects on people, property or property that may arise from a process. In common language the risk is often used in parallel with the probability of loss. Risks are often seen as the result of hazard characteristics (the physical characteristics of the hazard and its effects), vulnerability (vulnerability to sensitivity) and exposures. Risk can presented conceptually with the following equation:

Risk $=$ Hazard $*$ Vulnerability $*$ Exposures

In this study, we calculate risk by setting up criteria groups for hazards, vulnerability and exposures.

\subsection{Criteria for Hazards}

A hazard is a process, phenomenon or human activity that can cause a hazard casualties or other harm to health, property damage, socioeconomic disruption or environmental degradation. In this study, hazard criteria are defined as a combination of stability, flood factors and the overflow bridges safety.

\subsubsection{Stability Factor}

This factor considers the stability of human and vehicles under the impact of flood flow at the overflow bridges site. Value of water level and velocity at the work are characteristics to assess the instability of the object under the impact of flood flow (Figure 2a)

\subsubsection{Human Stability}

Human stability under the influence of flow is controlled by four factors: floating force $\left(\mathrm{F}_{\mathrm{b}}\right)$, thrust of flow $\left(\mathrm{F}_{\mathrm{D}}\right)$, body weight $\left(\mathrm{F}_{\mathrm{G}}\right)$ and reaction force $\left(\mathrm{F}_{\mathrm{n}}\right)$. Floating force $\left(\mathrm{F}_{\mathrm{b}}\right)$ is determined by (Junqiang Xia, 2014)(Junqiang Xia, 2014) as follows:

$$
F_{b}=g \rho_{f}\left(a_{1} x^{2}+b_{1} x\right)\left(a_{2} m_{p}+b_{2}\right)
$$

where

$\mathrm{g}$ is the gravitational acceleration $\left(\mathrm{m} / \mathrm{s}^{2}\right)$;

$\rho_{\mathrm{f}}$ is the density of water $\left(\mathrm{kg} / \mathrm{m}^{3}\right)$;

$\mathrm{x}=\mathrm{hf} / \mathrm{hp} ; \mathrm{h}_{\mathrm{f}}$ is the flow depth $(\mathrm{m}) ; \mathrm{h}_{\mathrm{p}}$ is the height of the person $(\mathrm{m})$;

$\mathrm{m}_{\mathrm{p}}$ is body weight $(\mathrm{kg})$;

$a_{1}$ and $b_{1}$ are constants. According the study of (T.D. Shand, 2011)(T.D. Shand, 2011) $a_{1}=$ 0.633 and $b_{1}=0.367$

$a_{2}$ and $b_{2}$ are determined based on the characteristics of Asians (Chinese) (Guo, 1995) whose values are respectively $1.015^{*} 10^{-3}\left(\mathrm{~m}^{3} / \mathrm{kg}\right)$ and $-4.927 * 10^{-3}\left(\mathrm{~m}^{3}\right)$. 


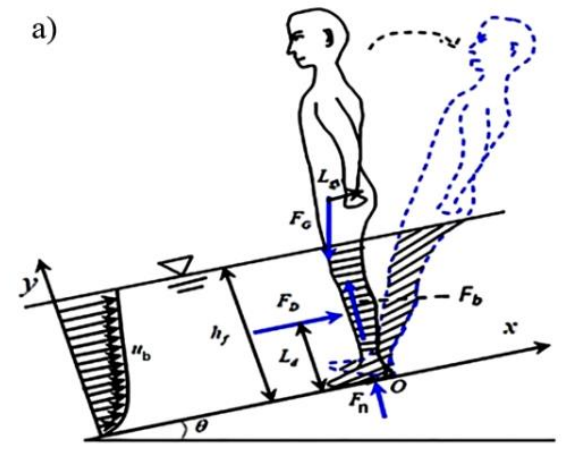

c)

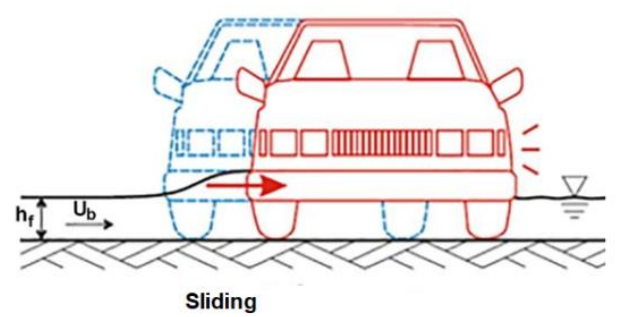

b)

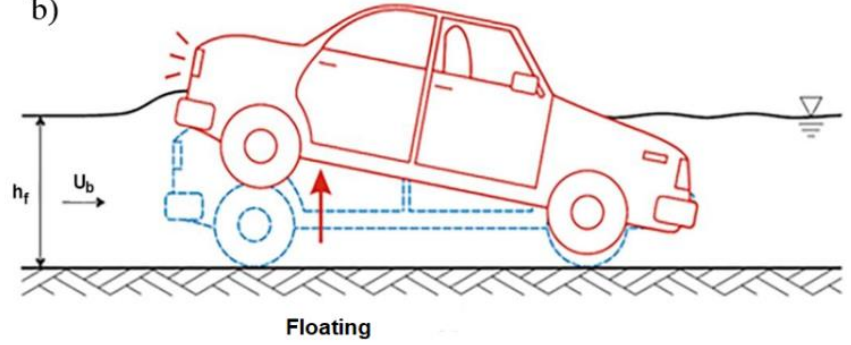

d)

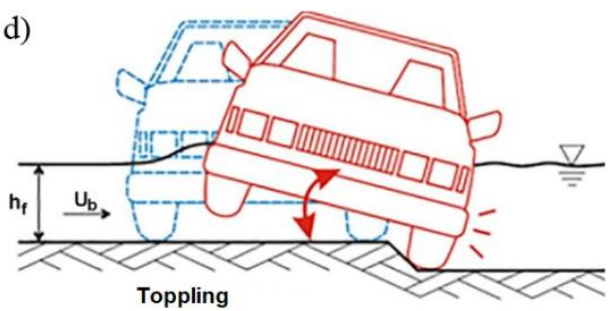

Figure 2 Typical modes human and vehicle instability (T.D. Shand, 2011)

The thrust of flow $\left(\mathrm{F}_{\mathrm{D}}\right)$ is determined by follows equation

$$
\mathrm{F}_{\mathrm{D}}=\frac{1}{2} \mathrm{~A}_{\mathrm{d}} \mathrm{C}_{\mathrm{d}} \rho_{\mathrm{f}} \mathrm{u}_{\mathrm{b}}^{2}
$$

where

$\mathrm{u}_{\mathrm{b}}$ is the velocity at the standing position $(\mathrm{m} / \mathrm{s})$;

$\mathrm{C}_{\mathrm{d}}$ is the drag coefficient;

$A_{d}$ is the area of the wet cross-section $\left(\mathrm{m}^{2}\right)$, determined by the formula

$\mathrm{A}_{\mathrm{d}}=\mathrm{a}_{\mathrm{d}} * \mathrm{a}_{\mathrm{p}} * \mathrm{~h}_{\mathrm{f}} * \mathrm{~h}_{\mathrm{p}}$, when the submerged section is below the waist, $\mathrm{a}_{\mathrm{d}}=\mathrm{a}_{\mathrm{p}}=0.19$.

Human body weight $\left(\mathrm{F}_{\mathrm{G}}\right)$ is divided into 2 force components in the $\mathrm{x}$ and $\mathrm{y}$ directions:

$$
\begin{aligned}
& F_{G x}=m_{p} g \sin \theta \\
& F_{G y}=m_{p} g \cos \theta-F_{b} \\
& \text { Reaction force } \quad F_{n}=F_{G y}
\end{aligned}
$$

Stabilization condition is defined as the possibility of being overturned around point $\mathrm{O}$ (Figure 2a). The moment balance at point $\mathrm{O}$ is given by the equation:

$$
\mathrm{F}_{\mathrm{Gy}} \mathrm{L}_{\mathrm{Gy}}+\mathrm{F}_{\mathrm{Gx}} \mathrm{L}_{\mathrm{Gx}}=\mathrm{F}_{\mathrm{D}} \mathrm{L}_{\mathrm{d}}
$$

where: $\mathrm{L}_{\mathrm{d}}=\mathrm{a}_{\mathrm{h}} \mathrm{h}_{\mathrm{f}} ; \mathrm{L}_{\mathrm{Gx}}=\mathrm{a}_{\mathrm{Gx}} \mathrm{h}_{\mathrm{p}}$ và $\mathrm{L}_{\mathrm{Gy}}=\mathrm{aGy} \mathrm{hp} ; \mathrm{a}_{\mathrm{h}}=\mathrm{a}_{\mathrm{Gx}}=0.55$ (Hellebrandt, 1938); $\mathrm{a}_{\mathrm{Gy}}=$ 0.05 ( (Guo, 1995).

Substituting equations from (1) to (5) into (6), we can get the equation that determines the condition of stability in the flow:

$$
u_{b} h_{f}=\sqrt{\frac{2 g\left(m_{p} \cos \theta-\rho_{f}\left(a_{1} x^{2}+b_{1} x\right)\left(a_{2} m_{p}+b_{2}\right)\right) a_{G y}+m_{p} a_{G x} \sin \theta}{a_{d} a_{p} a_{h} C_{d} \rho_{f}}}
$$

Equation (7) shows that when $\mathrm{x}$ changes, the $\mathrm{u}_{\mathrm{b}} \mathrm{h}_{\mathrm{f}}$ criterion for human hardly changes, but only depends mainly on the change of $m_{p}$ (Figure $3 a$ ). Velocity values that endanger for human by weight for each depth of flood level are shown in Figure $3 b$. 


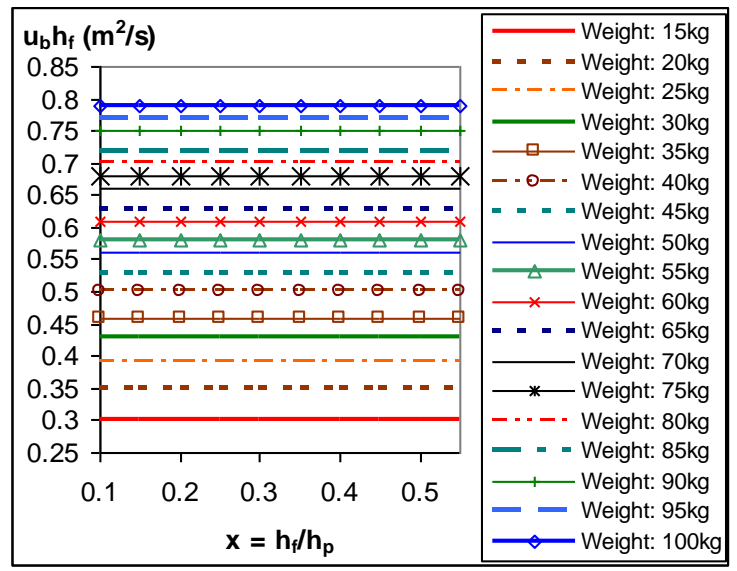

Figure 3a. Relationship between $\mathrm{u}_{\mathrm{b}} \mathrm{h}_{\mathrm{f}}$ and $\mathrm{x}$

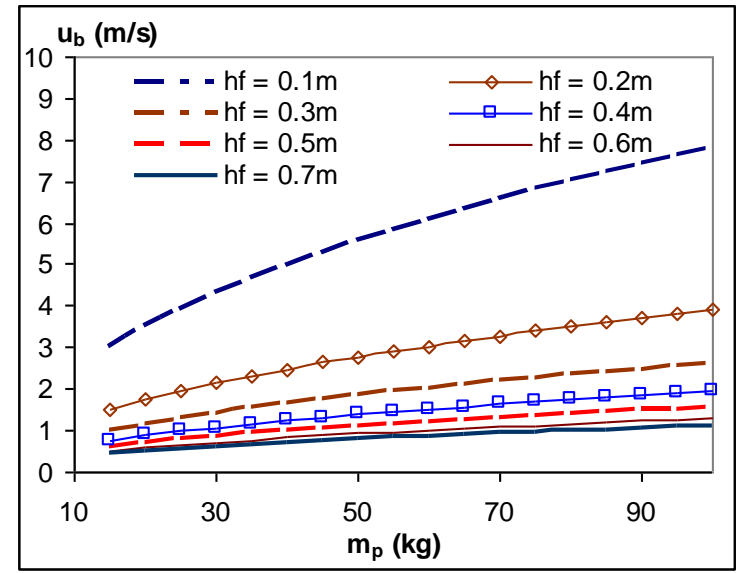

Figure 3b. Relationship between $\mathrm{u}_{\mathrm{b}}$ and $\mathrm{m}_{\mathrm{p}}$

According to the survey of nutrition of the Ministry of Health of Vietnam for adults aged 25 - 64 years in the North Central and South Central Coast of Vietnam, the average height of the people is $161.45 \mathrm{~cm}$ and weight ranges from $45-60 \mathrm{~kg}$, average $49.30 \mathrm{~kg}$. Therefore, the dangerous limit $\mathrm{u}_{\mathrm{b}} \mathrm{h}_{\mathrm{f}}$ is $0.5-0.6 \mathrm{~m}^{2} / \mathrm{s}$. Thus, the criteria for the stability of road users under the impact of flow are determined according to Table 2.

\subsubsection{Vehicles Stability}

Vehicles moving through flooded on overflow bridges areas are likely to be unstable due to floating or repulsive forces (Figure 2b, c, d). Some scientists have studied empirical and / or theory such as (Hattersley, 1967), (Foster, 1973), (Keller, 1993) for different vehicles such as Ford Falcon, Morris Mini, Toyota Corolla, Suzuki Swift, Ford Laser, Honda Civic, Ford LTD with different assumed coefficient of friction varying from 0.3 to 1.0 and mainly is 0.3 . The stability conditions for vehicles ranged from $0.2-1.2 \mathrm{~m}^{2} / \mathrm{s}$ (Keller, 1993).

Based on the guidance on the selection of technical scale of rural roads for the National Target Program on New Rural Construction period 2010-2020 according to Decision No. 4927 / QD-BGTVT (dated December 25, 2014) of The Ministry of Transport (Vietnam), the velocity values on the overflow bridge surface and the depth of flows are defined as Table 1 .

Table 1 Maximum depth of flow on overflow bridge

\begin{tabular}{|l|l|l|l|}
\hline Velocity on the overflow bridge surface, $\mathrm{u}_{\mathrm{c}}(\mathrm{m} / \mathrm{s})$ & $\leq 1.5$ & 2.0 & 2.5 \\
\hline Depth of flow, $\mathrm{h}_{\mathrm{f}}(\mathrm{m}$ & 0.4 & 0.3 & 0.2 \\
\hline
\end{tabular}

Thus, the selected $u_{c} h_{f}$ danger limit is $0.5-0.6 \mathrm{~m}^{2} / \mathrm{s}$. However, in order to improve safety indicators, the study selected safety threshold according to flood depth $h_{f}=0.3 \mathrm{~m}$ for all vehicles.

Table 2 Stability criteria

\begin{tabular}{|c|c|c|c|}
\hline \multicolumn{2}{|c|}{ Criterias } & \multirow{2}{*}{ Level } & \multirow{2}{*}{ Value } \\
\hline Human stability & Vehicles stability & Low danger & 1 \\
\hline $\mathrm{u}_{\mathrm{b}} \mathrm{h}_{\mathrm{f}}<0.5$ & $\mathrm{~h}_{\mathrm{f}} \leq 0.3$ & Medium danger & 2 \\
\hline $0.5<\mathrm{u}_{\mathrm{b}} \mathrm{h}_{\mathrm{f}}<0.6$ & $0.3<\mathrm{h}_{\mathrm{f}} \leq 0.4$ & High danger & 3 \\
\hline $\mathrm{u}_{\mathrm{b}} \mathrm{h}_{\mathrm{f}}>0.6$ & $\mathrm{~h}_{\mathrm{f}}>0.4$ & \\
\hline
\end{tabular}




\subsubsection{Flood Criteria}

Flood criteria are composed of three components including flood frequency, flood duration and flood intensity. Most spillways in the central region of Vietnam do not have hydrological monitoring stations, so the determination of this criterion depends on the results of the analysis of survey data.

Survey results show that in the recent 10 years, floods appear more frequently, on average about 2-4 times/year, while before only 1-2 times/year; The duration of inundation is usually from less than 1 day to 3 days; The average flood water level is about $0.3-0.5 \mathrm{~m} / \mathrm{h}$. Local people can estimate flooding time through weather forecasts. Floods of less than 1 day have little impact on traffic activities because the people have actively taken appropriate measures. When the flood time is more than 1 day, people have to go the other way or wait for the flood to recede. In floods with the intensity of less than $0.3 \mathrm{~m} / \mathrm{h}$, the people are completely able to cope.

According to survey results in more than 40 states in the US, (Motayed A K, 1982) identified flood frequency of less than 2 times / year as favorable, 10 times / year as disadvantage and duration of flood less than 1 day is favorable, 3 days is disadvantage. Therefore, flood criteria for flood frequency, duration of flooding and flood intensity are selected as in Table 3 .

Table 3 Flood criteria

\begin{tabular}{|c|c|c|c|c|}
\hline \multicolumn{3}{|c|}{ Flood criteria } & \multirow[b]{2}{*}{ Level } & \multirow[b]{2}{*}{ Value } \\
\hline Frequency & $\begin{array}{c}\text { Time } \\
\text { inundation }\end{array}$ & Intensity & & \\
\hline 1 time/year & $<1$ day & $<0.3 \mathrm{~m} / \mathrm{h}$ & Low danger & 1 \\
\hline $2-3$ times/year & 1-3 days & $0.3-0.5 \mathrm{~m} / \mathrm{h}$ & Medium danger & 2 \\
\hline > 3 times/year & $>3$ days & $>0.5 \mathrm{~m} / \mathrm{h}$ & High danger & 3 \\
\hline
\end{tabular}

\subsubsection{Overflow Bridge Criteria}

The overflow bridges in the central region of Vietnam are mostly built on inter-commune and inter-district roads of the type of small constructions with concrete and paved structures, so it is almost impossible to collect design documents. Therefore, the evaluation of construction safety according to the criteria of deformation, displacement, the formation and expansion of cracks in concrete, the degree of vandalism, erosion depends on the observation recorded by the investigator (Table 4)

Table 4 Overflow bridge criteria

\begin{tabular}{|l|l|c|}
\hline \multicolumn{1}{|c|}{ Criteria } & \multicolumn{1}{|c|}{ Level } & Value \\
\hline The original shape, no cracks, stable parts, no deformation & Low danger & 1 \\
\hline The original shape, but cracked, moved within the allowed limits & Medium danger & 2 \\
\hline Deformation, large cracked parts, roof slopes & High danger & 3 \\
\hline
\end{tabular}

\subsection{Criteria for Vulnerability}

Vulnerability means conditions defined by physical, social, economic and environmental factors or processes that can increase the sensitivity of an individual, community, property or system. affected by danger. This criterion is determined to aggregate the criteria of awareness, resilience; signs, warning systems; and bypass routes. 


\subsubsection{Awareness and Resilience of Local People}

This criterion is built based on the results of the survey for people in traffic and living around the work area by collecting multiple choice questionnaires with questions belonging to two groups of factors, including:

- Knowledge of people about floods when participating in traffic such as: Should or should not go through underground overflows when floods occur? How to identify the depth of flooding? How to capture flooded information?

- The ability of people to handle situations when they are swept away: Can they swim or not? What is the escape skill in a car swept away? How to rescue people swept away? How to rescue cars swept away?

Criteria for knowledge and resilience of the people selected are determined according to Table 5.

Table 5 Criteria of awareness and resilience

\begin{tabular}{|l|l|c|}
\hline \multicolumn{1}{|c|}{ Criteria } & \multicolumn{1}{c|}{ Level } & Value \\
\hline Meets over 70\% of multiple choice questions & Low danger & 1 \\
\hline Meet less than 70\% of multiple choice questions & Medium danger & 2 \\
\hline Meet less than 30\% of multiple choice questions & High danger & 3 \\
\hline
\end{tabular}

\subsubsection{Criteria for Signage, Warning Systems}

Warning system, signs on the underground work is responsible for bringing flood information to people in traffic. However, according to the survey results, this system is almost not equipped at underground works in central Vietnam (Figure 2). Criteria for signboards and warning systems are selected according to Table 6.

Table 6 Criteria for signage, warning systems

\begin{tabular}{|l|l|c|}
\hline \multicolumn{1}{|c|}{ Criteria } & \multicolumn{1}{c|}{ Level } & Value \\
\hline Warning systems, warning speakers available & Low danger & 1 \\
\hline Water column and signpost available & Medium danger & 2 \\
\hline $\begin{array}{l}\text { No warning systems, warning speakers and water } \\
\text { column }\end{array}$ & High danger & 3 \\
\hline
\end{tabular}

\subsubsection{The criteria for the Flood Avoidance Route}

The survey results of overflow bridges in central Vietnam showed that in mountainous areas, traffic density is low, roads are difficult to access, most have no bypass roads. The works in the delta areas have high traffic density, most of which have bypass routes. Currently, GPS applications have made it easier for road users to find an appropriate alternative route. Based on the status of the bypass routes, the study proposed evaluation criteria as follows (Table 7):

Table 7 The criteria for the flood avoidance route

\begin{tabular}{|l|l|c|}
\hline \multicolumn{1}{|c|}{ Criteria } & \multicolumn{1}{|c|}{ Level } & Value \\
\hline $\begin{array}{l}\text { Flood avoidance route available, the travel time is less than } \\
1 \text { hour }\end{array}$ & Low danger & 1 \\
\hline $\begin{array}{l}\text { Flood avoidance route available, the travel time is more } \\
\text { than 1 hour }\end{array}$ & Medium danger & 2 \\
\hline Flood avoidance route not available & High danger & 3 \\
\hline
\end{tabular}




\subsection{Criteria for Exposure}

Exposure is the state of the person, infrastructure, housing, production capacity and other tangible property which located in a vulnerable area. In this study, exposure was limited by people and vehicles through overflow bridge. The higher the density of traffic participation, the higher the risk and vice versa, so the number of turns of people and vehicles participating in traffic through the overflow bridge will be the specific factors for this criterion.

The study has carried out the monitoring of vehicle flow and traffic participants through some typical spillways in the central region of Vietnam. Monitoring data has determined the average daily flow of road users. Monitoring data showed that most of the underground spillways have the traffic of more than 50 people / day. According to (Motayed A K, 1982), if the means of traveling through overflow bridges traffic is less than 5 times / day is convenient and 200 times / day is disadvantage.

In order to ensure safety and suitability with construction characteristics, the study proposed the following vehicle density criteria (Table 8):

Table 8 Criteria for exposure

\begin{tabular}{|l|l|l|c|}
\hline \multicolumn{1}{|c|}{ Average number of vehicles } & \multicolumn{1}{c|}{ Number of people } & \multicolumn{1}{c|}{ Level } & Value \\
\hline Less than 50 vehicles/day & Less than 5 people & Low danger & 1 \\
\hline Less than 200 vehicles/day & Less than 20 people & Medium danger & 2 \\
\hline More than 200 vehicles/day & More than 20 people & High danger & 3 \\
\hline
\end{tabular}

\section{RESULTS AND DISCUSSION}

Survey results have shown that risks when people and vehicles through the overflow bridges mainly at the time of floods. Consequently vulnerability criteria related to people's awareness and ability to handle situations are the most important criteria. Besides, the warning system, signage, baries are the second most important factors causing risks. The flood avoidance route is the third most important factor to reduce the risk of traffic. Criteria for hazards related to flood intensity are the next important criteria because they are the criteria causing the sudden occurrence of floods. However, this criterion is dependent on each flood, so the assessment is only conducted when there are forecast results or for floods that have occurred. The remaining criteria are assessed to have a relatively uniform level of risk. The density of people and vehicles is only really strong when floods occur at a time of high density. However, at this time, it is almost impossible to estimate in advance because the forecast of the incoming flow in these areas is limited. Therefore, this criterion only assesses the average daily traffic volume and the level of risk divided evenly across the time of day. Impact of works safety on road users is taken into consideration when road users through flood flow have limited visibility of the building surface, the building deformation can increase risks.

To estimate the weights of the factors, we used the Analytic Hierarchy Process (AHP) method (Saaty, 1980) for 10 factors belonging to 3 groups of criteria: Hazard, vulnerability and exposure. Factors as mentioned above, including: Frequency of flood, duration of flood, intensity of flood, density of people and vehicles, human stability, vehicles stability, warning systems, avoidance routes, structural work, and awareness and resilience of local people. Weights are calculated based on matrix of $10 \times 10$ elements and 45 comparison pairs (Table 9 and 10) 
Hoang Ngoc Tuan, Nguyen Van Luc, Hoang Nam Binh and Hoang Duc Vinh

Table 9 Pair-wise comparison matrix

\begin{tabular}{|c|c|c|c|c|c|c|c|c|c|c|}
\hline Factors & $\begin{array}{c}\text { Frequen } \\
\text { cy of } \\
\text { flood } \\
\end{array}$ & $\begin{array}{c}\text { Duratio } \\
\text { n of } \\
\text { flood }\end{array}$ & $\begin{array}{c}\text { Intensit } \\
\text { y of } \\
\text { flood }\end{array}$ & $\begin{array}{c}\text { Density of } \\
\text { people and } \\
\text { vehicles } \\
\end{array}$ & $\begin{array}{c}\text { Huma } \\
\mathbf{n} \\
\text { stabilit } \\
\mathbf{y} \\
\end{array}$ & $\begin{array}{c}\text { Vehicle } \\
\text { s } \\
\text { stabilit } \\
y \\
\end{array}$ & $\begin{array}{c}\text { Warnin } \\
\text { g } \\
\text { systems }\end{array}$ & $\begin{array}{c}\text { Avoida } \\
\text { nce } \\
\text { routes } \\
\end{array}$ & $\begin{array}{c}\text { Struct } \\
\text { ural } \\
\text { work }\end{array}$ & $\begin{array}{c}\text { Awareness } \\
\text { and } \\
\text { resilience }\end{array}$ \\
\hline $\begin{array}{l}\text { Frequency of } \\
\text { flood }\end{array}$ & 1 & 1 & 0.5 & 1 & 1 & 5 & 1 & 0.5 & 1 & 0.2 \\
\hline $\begin{array}{l}\text { Duration of } \\
\text { flood }\end{array}$ & 1 & 1 & 0.5 & 1 & 1 & 1 & 0.2 & 0.5 & 1 & 0.2 \\
\hline $\begin{array}{l}\text { Intensity of } \\
\text { flood }\end{array}$ & 2 & 2 & 1 & 2 & 2 & 2 & 0.5 & 1 & 2 & 0.5 \\
\hline $\begin{array}{l}\text { Density of } \\
\text { people and } \\
\text { vehicles }\end{array}$ & 1 & 1 & 0.5 & 1 & 1 & 1 & 0.2 & 0.5 & 1 & 0.2 \\
\hline $\begin{array}{l}\text { Human } \\
\text { stability }\end{array}$ & 1 & 1 & 0.5 & 1 & 1 & 1 & 0.2 & 0.5 & 1 & 0.2 \\
\hline $\begin{array}{l}\text { Vehicles } \\
\text { stability }\end{array}$ & 0.2 & 1 & 0.5 & 1 & 1 & 1 & 0.2 & 0.5 & 1 & 0.2 \\
\hline $\begin{array}{l}\text { Warning } \\
\text { systems }\end{array}$ & 1 & 5 & 2 & 5 & 5 & 5 & 1 & 2 & 5 & 1 \\
\hline $\begin{array}{l}\text { Avoidance } \\
\text { routes }\end{array}$ & 2 & 2 & 1 & 2 & 2 & 2 & 0.5 & 1 & 2 & 0.5 \\
\hline $\begin{array}{l}\text { Structural } \\
\text { work }\end{array}$ & 1 & 1 & 0.5 & 1 & 1 & 1 & 0.2 & 0.5 & 1 & 0.2 \\
\hline $\begin{array}{l}\text { Awareness } \\
\text { and resilience }\end{array}$ & 5 & 5 & 2 & 5 & 5 & 5 & 1 & 2 & 5 & 1 \\
\hline
\end{tabular}

Table 10 The result of calculating the weight of the factors

\begin{tabular}{|c|l|c|c|}
\hline No & \multicolumn{1}{|c|}{ Factors } & Weights & Rank \\
\hline 1 & Frequency of flood & $8.40 \%$ & 5 \\
\hline 2 & Duration of flood & $5.10 \%$ & 6 \\
\hline 3 & Intensity of flood & $10.60 \%$ & 3 \\
\hline 4 & Density of people and vehicles & $5.10 \%$ & 6 \\
\hline 5 & Human stability & $5.10 \%$ & 6 \\
\hline 6 & Vehicles stability & $4.40 \%$ & 10 \\
\hline 7 & Warning systems & $21.20 \%$ & 2 \\
\hline 8 & Avoidance routes & $10.60 \%$ & 3 \\
\hline 9 & Structural work & $5.10 \%$ & 6 \\
\hline 10 & Awareness and resilience & $24.40 \%$ & 1 \\
\hline
\end{tabular}

The consistency ratio $(C R)=0.03$

Table 10 showed that there are $3^{10}$ series of numbers selected. The distribution of the results of the assessment of overflow bridges risks in Central Vietnam is shown in Figure 3 with the largest total value of 3 at $0 \%$ and the smallest of 1 at $100 \%$. The result of assessing the danger of overflow bridges based on frequency distribution, if greater than $85 \%$ is considered as low danger, less than $50 \%$ is high danger, the remaining is medium danger (Table 11).

Table 11 Summing up the criteria

\begin{tabular}{|l|l|}
\hline \multicolumn{1}{|c|}{ Criteria } & \multicolumn{1}{c|}{ Level } \\
\hline $1,0 \leq \mathrm{C}<1,66$ & Low danger \\
\hline $1,66 \leq \mathrm{C}<2,0$ & Medium danger \\
\hline $2,0 \leq \mathrm{C} \leq 3,0$ & High danger \\
\hline
\end{tabular}




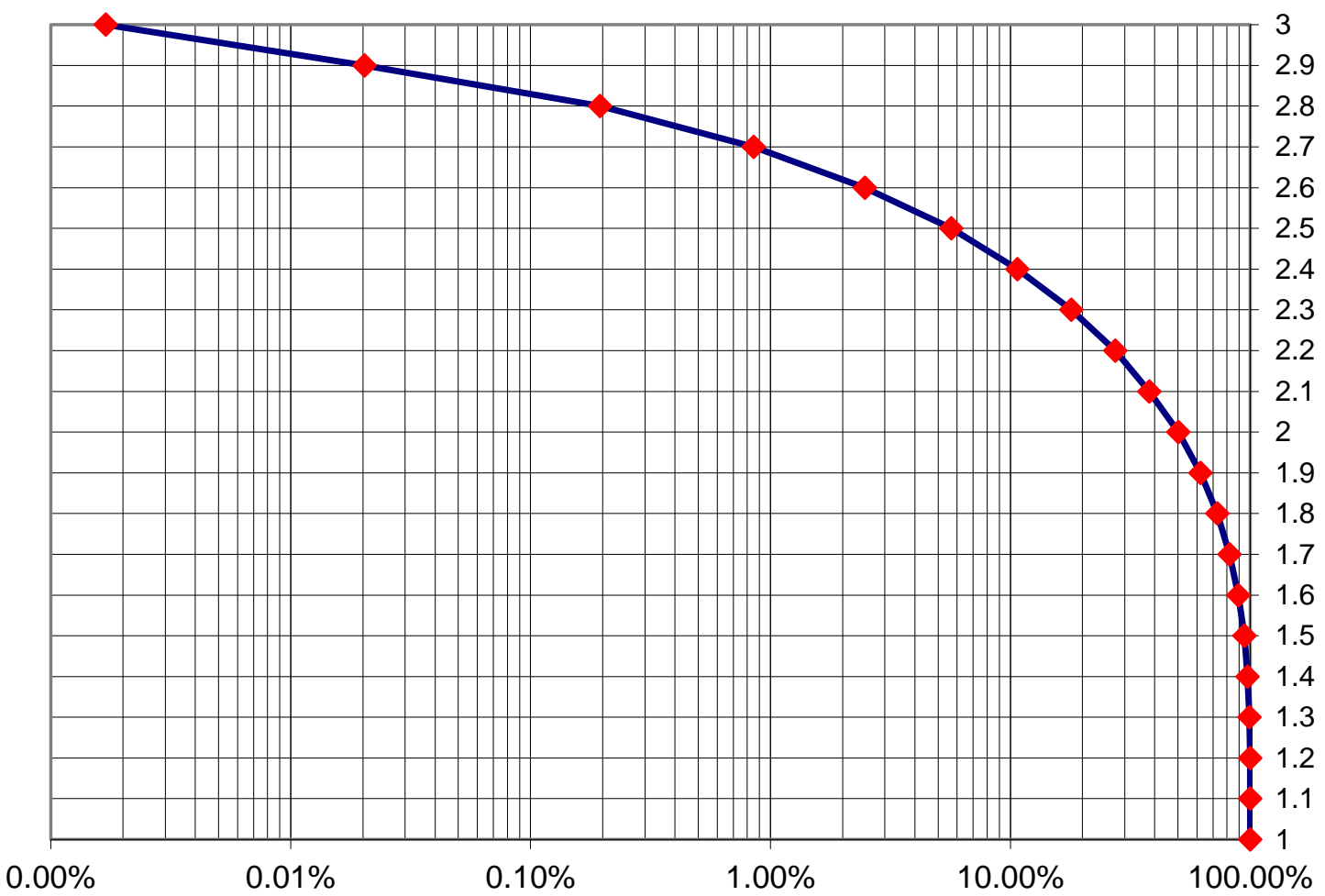

Figure 3 Risk distribution at overflow bridges

\section{CONCLUSION}

The application of a set of criteria to assess the danger of overflow bridge is very meaningful in practice. However, when applied, it is necessary to be flexible in specific conditions of each region in order to get the most accurate results. For managers, it is essential to understand the danger of $\mathrm{s}$ overflow bridge. Based on this, it is possible to offer the most optimal solutions to minimize the damage or to list the construction of works in order of priority.

Currently, it is difficult to invest in upgrading all the overflow bridge, so it is necessary to find solutions to cope. In particular, raising awareness of the community combined with the construction of automatic warning systems in the overflow bridge will be the most economical and effective solution.

When constructing new or repairing, upgrading overflow bridge, it is necessary to comprehensively consider the alternatives, which can both be a bridge to overcome large floods, and an overflow bridge to overcome small floods to reduce cost of construction.

\section{ACKNOWLEDGEMENT}

This paper is the result of a research project of the state level "Researching and assessing flood risks of overflow bridge in Vietnam central and proposing an early warning system" under the program "Scientific research and technology for environmental protection and disaster prevention" code KC.08.03 /16-20, Vietnam 


\section{REFERENCES}

[1] Alexander, D., (1997). The study of Natural Disasters, 1977-1997: Some reflections on a changing field of knowledge. Disasters, pp. 284-304.

[2] A J Bonham and R T Hattersley, (1967). Low level causeways. University of New South Wales, Water Research Laboratory, Technical Report 100, New South Wales, Australia.

[3] Foster, D.N., Cox, R.J., (1973). Stability of children on roads used as floodways. Report of Water Research Laboratory, Australia.

[4] Junqiang Xia, R. A. F. Y. W. X. X., (2014). New criterion for the stability of a human body in floodwaters. Journal of Hydraulic Research, 52(1(2014)), p. 93-104.

[5] Guo, Q.S., Wang, Y.H., (1995). Ergonomics. Tianjing University Press, Tianjing (in Chinese)

[6] Hellebrandt, F. A. (1938). Standing, a geotropic reflex, the mechanism of the asynchronous rotation of motor units. Amer. J. Physiol. 121: 471-474.

[7] Keller, R.J., Mitsch, B., (1993). Safety aspects of design roadways as floodways. Research Report No. 69, Urban Water Research Association of Australia, Melbourne Australia.

[8] Motayed A K, Chang F M, Mukherjee D K., (1982). Design and construction of low water stream crossings. Final report.

[9] Saaty, T., (1980). The analytic hierarchy process. McGraw-Hill, New York.

[10] T.D. Shand, G. R. a. M., (2011). Development of Appropriate Criteria for the Safety and Stability of Persons and Vehicles in Floods. Brisbane, Australia, Proceedings of the 34th World Congress of the International Association for Hydro- Environment Research and Engineering: 33rd Hydrology and Water Resources Symposium and 10th Conference on Hydraulics in Water Engineering. 